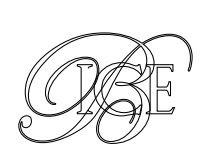

\title{
LAS RELACIONES COMERCIALES Y DE INVERSIÓN ENTRE ESPAÑA Y JAPÓN: PRESENTE Y PERSPECTIVAS
}

En este artículo se expone la situación actual de las relaciones comerciales bilaterales y de inversión, y se examinan las nuevas oportunidades de mercado como consecuencia de la entrada en vigor este año del Acuerdo de Asociación Económica (EPA) entre la UE y Japón. Se hace especial hincapié también en el programa PASE (Países con Actuación Sectorial Estratégica) diseñado para ese país asiático y en la agenda institucional como actuaciones para fomentar los flujos comerciales y la inversión. Además de las oportunidades de mercado, se valora la cooperación entre empresas de ambos países en proyectos conjuntos con la posibilidad de cofinanciación en paralelo (FIEM).

Palabras clave: exportación, importación, inversión internacional, internacionalización, Acuerdo de Asociación Económica (EPA), instrumento de apoyo a la internacionalización de la empresa española FIEM.

Clasificación JEL: F14, O53.

\section{Introducción: marco general de las relaciones económicas}

Las relaciones bilaterales hispano-japonesas se encuentran en un momento óptimo como consecuencia del impulso experimentado en los planos institucional y económico-comercial durante los últimos años.

La celebración del Año Dual de EspañaJapón en 2013 y 2014 sirvió para reforzar los contactos institucionales y empresariales.

* Este artículo ha sido elaborado por Alfonso M. Jiménez Murcia, Jefe de Área de la Subdirección General de Asia, Europa no Unión Europea y Oceanía. Dirección General de Comercio Internacional e Inversiones.

Versión de septiembre de 2019.

DOI: https:/doi.org/10.32796/bice.2019.3115.6911
Una vez clausurado el Año Dual, continuaron reforzándose las visitas institucionales y las iniciativas destinadas a promover las relaciones económicas y comerciales bilaterales.

Por su parte, SS MM los Reyes de España visitaron Japón, en abril de 2017, acompañados de una nutrida delegación, y en 2018 se conmemoró el 150 aniversario del establecimiento de relaciones diplomáticas entre ambos países ${ }^{1}$.

A su vez, en octubre de 2018, el primer ministro Abe visitó oficialmente España, acompañado de seis viceministros japoneses, y se adoptó una nueva Declaración Conjunta, que en esta ocasión se calificó de Asociación Estratégica. $\triangleright$

1 El 12 de noviembre de 1868, Japón y España firmaron el Tratado de Amistad, Comercio y Navegación. Mediante este tratado, ambos países establecieron relaciones diplomáticas y comerciales. 
Además de las relaciones institucionales, las actividades bilaterales promovidas por el sector privado también han contribuido a profundizar la amistad entre nuestros dos países durante los últimos 150 años.

Este contexto general tan positivo se apoya, además, en una serie de programas y acuerdos en materia económica y comercial que suponen una base sólida para el presente y futuro de la relación bilateral, entre los que podemos citar, por su importancia y repercusión, el Memorándum de Entendimiento (MOU) entre el entonces Ministerio de Economía, Industria y Competitividad y el Ministerio de Economía, Comercio e Industria de Japón $\left(\mathrm{METI}^{2}\right)$ sobre cooperación económica e industrial (2017); el MOU ${ }^{3}$ ICEX ${ }^{4}$ JETRO $^{5}$ de colaboración y cobertura logística en terceros países (2013); el MOU bilateral $\mathrm{ICO}^{6}-\mathrm{JBIC}^{7}$ de financiación conjunta de operaciones en terceros países (2013); el Convenio para evitar la Doble Imposición de 1974 (BOE de 2 de diciembre de 1974 y el nuevo Convenio firmado en octubre de 2018); y el MOU entre JBIC y el Ministerio de Industria, Turismo y Comercio de España para la concesión de créditos a interés preferencial para operaciones conjuntas hispano-japonesas, firmado en 2010.

A estos acuerdos se suman los denominados protocolos bilaterales, que autorizan la exportación española a Japón de determinados productos agropecuarios.

Y, además, en julio de 2018 se firmó el Acuerdo de Asociación Económica (EPA, por sus siglas en inglés) entre la UE y Japón, cuya entrada en vigor tuvo lugar el 1 de febrero de 2019.

\footnotetext{
Ministry of Economy, Trade and Industry of Japan.

Memorandum of Understanding.

ICEX España Exportación e Inversiones.

Japan External Trade Organization.

Instituto de Crédito Oficial.

Japan Bank for International Cooperation.
}

\section{Relaciones comerciales y de inversión}

Es de destacar la relación especial entre España y Japón, dos países que se encuentran a más de $10.000 \mathrm{~km}$ de distancia y entre los que no hubo apenas relaciones comerciales hasta los años cincuenta del siglo xx, habiendo experimentado desde entonces los intercambios comerciales bilaterales una transformación notable, particularmente en los últimos años.

La implantación de empresas japonesas en España en la década de los setenta tiene su origen en los procesos de liberalización, reorganización, aprendizaje y capitalización que tenían como objetivo la internacionalización de la economía nipona en los años setenta y ochenta ${ }^{8}$. Sin embargo, es a partir de 1985 cuando la inversión industrial japonesa en España ${ }^{9}$ empieza a tener una cierta entidad.

Desde entonces, las relaciones económicas bilaterales han evolucionado positivamente $y$ han alcanzado unas cifras realmente importantes, como se expone a continuación.

\subsection{Comercio de bienes}

En la actualidad, el valor de las exportaciones españolas se ha duplicado desde el comienzo de la crisis, pasando de 1.213 millones de euros en 2009 a 2.528 millones de euros en 2018.

\footnotetext{
8 Este proceso de internacionalización se dio como continuidad natural de otra fase anterior de liberalización de la economía tras la II Guerra Mundial, necesaria para poner al día legislación e instituciones que permanecían sin apenas cambios desde la época Meiji.

9 España, a mediados de los ochenta, era un país que comenzaba a mostrar indicadores de país desarrollado, con unos mercados que por tamaño y perspectivas de crecimiento resultaban ya atractivos para las empresas japonesas. Además, pertenecía a los principales organismos internacionales y era miembro del Mercado Común, y, algo nada desdeñable, países de otros grandes grupos ya habían apostado antes por el nuestro.
} 
Las exportaciones de productos no energéticos aumentaron en 2018 por noveno año consecutivo, alcanzando los 2.526 millones de euros (máximo valor de la serie histórica). Las exportaciones de productos energéticos, sin embargo, han registrado una evolución diferente ${ }^{10}$. Las importaciones españolas procedentes de Japón registraron en 2007 su máximo valor, 6.082 millones de euros, y se redujeron progresivamente hasta llegar a los 2.437 millones de euros en 2013. Desde entonces se han ido recuperando, aunque solo parcialmente, hasta alcanzar los 4.132 millones de euros en 2018.

Como consecuencia de lo anterior, en el ámbito del comercio de mercancías se ha pasado de una cobertura del saldo exportador del $28,5 \%$ en 2004 al $61,1 \%$ en 2018 . El número de empresas exportadoras de mercancías a Japón en 2018 fue de 9.084, incrementándose frente a las registradas en 2017 (8.993 empresas) y 2016 (7.011 empresas).

10 Esta evolución estuvo ligada con la situación creada tras el maremoto ocurrido en marzo de 2011.
En el año 2018, España fue el sexto suministrador de Japón de entre los países de la UE, con unas ventas que supusieron el 0,4\% de las importaciones del país asiático. Para España, Japón ocupó en este periodo el puesto 16 como cliente, con una cuota del 0,9\%. En 2018, a España le correspondió el puesto 28 como mercado de destino de las exportaciones japonesas y el 30 como país de origen de sus importaciones.

En 2018, las exportaciones españolas a Japón aumentaron un 3,4\% respecto a 2017.

Los principales productos clasificados dentro del código TARIC de las ventas procedentes de nuestro país fueron: carne y despojos comestibles $(20,2 \%)$, productos farmacéuticos $(15,2 \%)$, vehículos automóviles y tractores $(13,4 \%)$, grasas y aceites de origen animal o vegetal $(5,5 \%)$, minerales, escorias y cenizas $(3,3 \%)$, prendas de vestir $(6,8 \%)$, pescados, crustáceos y moluscos $(1,8 \%)$, bebidas de todo tipo, excepto zumos $(3,5 \%)$, y productos químicos inorgánicos $(3,2 \%)$.

CUADRO 1

FLUJOS COMERCIALES ESPAÑA-JAPÓN

(En millones de euros)

\begin{tabular}{|l|c|c|c|r|r|}
\hline \multicolumn{1}{|c|}{ Flujos } & $\mathbf{2 0 1 5}$ & $\mathbf{2 0 1 6}$ & $\mathbf{2 0 1 7}$ & $\mathbf{2 0 1 8}$ & $\mathbf{2 0 1 9}$ (ene-jun) \\
\hline Exportación & $2.470,1$ & $2.405,7$ & $2.446,3$ & $2.527,6$ & $1.255,2$ \\
Importación & $3.217,8$ & $3.639,3$ & $3.928,3$ & $4.132,1$ & $2.244,3$ \\
Saldo balanza & $-747,7$ & $-1.233,7$ & $-1.482,1$ & $-1.604,6$ & $-989,1$ \\
Tasa cobertura (\%) & 76,8 & 66,1 & 62,3 & 61,2 & 55,9 \\
Volumen comercio & $5.687,9$ & $6.045,0$ & $6.374,6$ & $6.659,7$ & $3.499,4$ \\
\hline \multicolumn{5}{|l}{ Fuente: DataComex y elaboración propia. }
\end{tabular}

CUADRO 2

EVOLUCIÓN INTERANUAL DE LOS FLUJOS COMERCIALES ESPAÑA-JAPÓN

(En porcentaje)

\begin{tabular}{|c|c|c|c|c|}
\hline Flujos & 2015-16 & 2016-17 & 2017-18 & 2018-19 (ene-jun) \\
\hline Exportación & $-2,6$ & 1,7 & 3,3 & 0,7 \\
\hline Importación & 13,1 & 7,9 & 5,2 & 1,5 \\
\hline Saldo balanza & 65,0 & 20,1 & 8,3 & 2,5 \\
\hline Tasa cobertura & $-13,9$ & $-5,8$ & $-1,8$ & $-0,8$ \\
\hline Volumen comercio & 6,3 & 5,5 & 4,5 & 1,2 \\
\hline
\end{tabular}


Los productos que más crecieron en el año 2018, comparado con el mismo periodo del año anterior, fueron los pescados, crustáceos y moluscos $(44,1 \%)$ y los minerales, escorias y cenizas $(22,3 \%)$, mientras que disminuyeron significativamente los vehículos automóviles y tractores $(-8,7 \%)$ y las grasas, aceite animal o vegetal $(-8,1 \%)$.

En el año 2018, las importaciones se incrementaron un 5,0\% en comparación con el mismo periodo de 2017.

Los productos TARIC más destacados en las compras españolas en este periodo fueron: vehículos automóviles y tractores (52,6\%), maquinaria y aparatos mecánicos $(18,1 \%)$, aparatos y material eléctrico $(9,4 \%)$, aparatos ópticos, de medida y medición $(5,4 \%)$, productos químicos orgánicos $(2,3 \%)$, materiales plásticos y sus manufacturas $(1,9 \%)$, otros productos químicos $(1,2 \%)$, caucho y sus manufacturas $(1,1 \%)$, productos farmacéuticos $(1,0 \%)$ y combustibles, aceites minerales (0,4\%).

En el año 2018, los productos de importación que más crecieron comparados con el año anterior fueron los combustibles y aceites minerales $(226,9 \%)$ y los productos químicos orgánicos materiales $(29,7 \%)$, mientras que los que más disminuyeron fueron los productos farmacéuticos $(-10,7 \%)$ y el caucho y sus manufacturas $(-2,2 \%)$.

En enero-junio de 2019, España fue el sexto suministrador de entre los países de la UE, con unas ventas que supusieron el $0,46 \%$ de las importaciones de Japón. Para España, $\triangleright$

CUADRO 3

PRINCIPALES PRODUCTOS EXPORTADOS A JAPÓN

(En millones de euros)

\begin{tabular}{|c|c|c|c|c|}
\hline Principales exportaciones & 2018 & 2019 (ene-jun) & $\% 2018$ & $\% 2019$ \\
\hline Carne y despojos comestibles & 251,62 & 247,85 & 20,2 & 19,7 \\
\hline Carne de porcino & 241,92 & 239,70 & 19,4 & 19,1 \\
\hline Productos farmacéuticos & 189,11 & 158,01 & 15,2 & 12,6 \\
\hline Medicamentos & 180,30 & 145,24 & 14,5 & 11,6 \\
\hline Vehículos automóviles y partes & 166,50 & 113,40 & 13,4 & 9,0 \\
\hline Accesorios de automoción & 117,89 & 91,51 & 9,5 & 7,3 \\
\hline Turismos & 45,26 & 17,01 & 3,6 & 1,4 \\
\hline Grasas y aceites & 68,19 & 86,36 & 5,5 & 6,9 \\
\hline Aceite de oliva & 60,54 & 77,29 & 4,9 & 6,2 \\
\hline Prendas de vestir & 57,55 & 54,55 & 6,8 & 4,3 \\
\hline Bebidas excepto zumos & 43,27 & 55,65 & 3,5 & 4,4 \\
\hline Vino & 36,49 & 46,72 & 2,9 & 3,7 \\
\hline Minerales, escorias y cenizas & 41,61 & 81,93 & 3,3 & 6,5 \\
\hline Escorias, cenizas y residuos & 41,39 & 81,87 & 3,3 & 6,5 \\
\hline Productos químicos inorgánicos & 39,77 & 57,48 & 3,2 & 4,6 \\
\hline Conservas de fruta y verdura & 31,03 & 26,75 & 2,5 & 2,1 \\
\hline Manufacturas de hierro y acero & 26,06 & 13,80 & 2,1 & 1,1 \\
\hline Aparatos y material eléctrico & 24,74 & 21,80 & 2,0 & 1,7 \\
\hline Manufacturas de cuero y marroquinería & 23,90 & 23,65 & 1,9 & 1,9 \\
\hline Materias plásticas & 22,82 & 23,35 & 1,8 & 1,9 \\
\hline Pescado y marisco & 22,67 & 30,69 & 1,8 & 2,4 \\
\hline Total exportación a Japón & $1.246,71$ & $1.255,16$ & 100,0 & 100,0 \\
\hline
\end{tabular}


Japón ocupó en este periodo el puesto 20 como cliente, con una cuota del $0,85 \%$.

En ese mismo periodo a España le correspondió el puesto 27 como mercado de destino de las exportaciones japonesas y el 29 como país origen de sus importaciones.

Los principales productos clasificados dentro del código TARIC de las exportaciones procedentes de nuestro país fueron: carne y despojos comestibles $(19,7 \%)$, productos farmacéuti$\cos (12,6 \%)$, vehículos automóviles y tractores $(9,0 \%)$, minerales, escorias y cenizas $(6,5 \%)$, grasas y aceites de origen animal o vegetal $(6,9 \%)$, productos químicos inorgánicos $(4,6 \%)$, prendas de vestir $(4,3 \%)$, bebidas de todo tipo, excepto zumos $(4,4 \%)$, y pescados, crustáceos y moluscos $(2,4 \%)$.

Los productos que más crecieron en enero-junio de 2019, comparado con el mismo periodo del año anterior, fueron los minerales, escorias y cenizas $(125,4 \%)$ y los productos químicos orgánicos $(63,0 \%)$, mientras que disminuyeron significativamente los vehículos automóviles y tractores $(-35,5 \%)$ y los productos farmacéuticos (-26,5\%).

En enero-junio de 2019 los productos TARIC más destacados en las importaciones españolas en este periodo fueron los vehículos automóviles y tractores $(51,0 \%)$, maquinaria y aparatos mecánicos $(19,1 \%)$, aparatos y materiales eléctricos $(9,5 \%)$, aparatos ópticos de medida y medición $(5,1 \%)$, productos químicos orgánicos $(2,7 \%)$, combustibles y aceites minerales $(1,4 \%)$, materiales plásticos y sus manufacturas $(1,8 \%)$, otros productos químicos $(1,1 \%)$ y caucho y sus manufacturas $(1,0 \%)$.

En enero-junio de 2019 los productos de importación que más crecieron, si los comparamos con el mismo periodo del año anterior, fueron los combustibles, aceites minerales $(598,0 \%)$ y los productos químicos orgánicos $(41,4 \%)$, mientras que los que más disminuyeron fueron otros productos químicos $(-15,2 \%)$ y los aparatos ópticos, de medida y medición (-13,6\%). $\triangleright$

CUADRO 4

PRINCIPALES PRODUCTOS IMPORTADOS DE JAPÓN

(En millones de euros)

\begin{tabular}{|c|c|c|c|c|}
\hline Productos & 2018 & 2019 (ene-jun) & $\% 2018$ & \% 2019 \\
\hline Vehículos y sus partes & $1.164,38$ & $1.143,94$ & 52,6 & 51,0 \\
\hline Turismos & 849,91 & 850,96 & 38,4 & 37,9 \\
\hline Maquinaria y equipo mecánico & 401,35 & 429,50 & 18,1 & 19,1 \\
\hline Material eléctrico & 208,00 & 214,25 & 9,4 & 9,5 \\
\hline Aparatos ópticos y de medida & 119,44 & 114,70 & 5,4 & 5,1 \\
\hline Productos químicos orgánicos & 50,13 & 60,94 & 2,3 & 2,7 \\
\hline Materias plásticas & 41,85 & 40,90 & 1,9 & 1,8 \\
\hline Otros productos químicos & 26,89 & 24,70 & 1,2 & 1,1 \\
\hline Caucho y sus manufacturas & 24,27 & 22,71 & 1,1 & 1,0 \\
\hline Productos farmacéuticos & 21,26 & 22,50 & 1,0 & 1,0 \\
\hline Manufacturas de fundición hierro/acero & 18,05 & 16,48 & 0,8 & 0,7 \\
\hline Combustibles & 9,95 & 31,77 & 0,4 & 1,4 \\
\hline Níquel & 9,86 & 11,00 & 0,4 & 0,5 \\
\hline Prod. fotografía y cinematografía & 8,88 & 8,20 & 0,4 & 0,4 \\
\hline Herramientas y cuchillería metálica & 8,49 & 9,20 & 0,4 & 0,4 \\
\hline Tanino y materias colorantes & 8,25 & 9,42 & 0,4 & 0,4 \\
\hline Total importación de Japón & $2.212,07$ & $2.244,28$ & 100,0 & 100,0 \\
\hline
\end{tabular}




\subsection{Comercio de servicios}

En el ámbito de los servicios, los intercambios en 2018 alcanzaron un valor aproximado ${ }^{11}$ de 1.500 millones de euros con un saldo favorable a España durante los últimos cuatro años.

CUADRO 5

COMERCIO DE SERVICIOS ESPAÑA-JAPÓN

(En millones de euros)

\begin{tabular}{|l|c|c|c|}
\hline \multicolumn{1}{|c|}{ Años } & Ingresos & Pagos & Saldo \\
\hline 2015 & 914 & 375 & 539 \\
2016 & 827 & 380 & 447 \\
2017 & 996 & 350 & 646 \\
2018 & 1.161 & 359 & 802 \\
\hline \multicolumn{4}{|l|}{ Fuente: Banco de España, Balanza de Pagos. } \\
\hline
\end{tabular}

\subsection{Inversiones}

De acuerdo con los últimos datos disponibles, el flujo de inversión japonesa bruta en España en 2014 marcó un récord histórico (460 millones de euros), superado en 2015 (555

11 Datos del Banco de España. En 2018: 1.161 millones de euros de ingresos y 350 millones de euros de pagos. millones de euros). En 2016 su valor fue de 509 millones de euros y en 2017 se redujo a 161,6 millones de euros. En 2018 se alcanzó un nuevo récord, 899 millones de euros. En el periodo enero-marzo de 2019 se ha alcanzado la cifra de 72,8 millones de euros.

Los flujos de inversión bruta directa española dirigidos a Japón ofrecen unas cifras más modestas: en 2017 fueron de 3,0 millones de euros y en 2018 , de 309.000 de euros.

La posición de inversión (stock) de Japón en España era de 6.712,4 millones de euros en 2017. En cuanto a la inversión española en Japón, dicho stock era de 272,8 millones de euros ese año.

Japón es el 12.ำ inversor en España y nuestro país, el $61 .^{\circ}$ en Japón.

\section{Oportunidades de mercado}

A pesar de la mejora experimentada por las relaciones económicas hispano-japonesas, existe un amplio margen para continuar impulsando y reforzando los intercambios $D$

CUADRO 6

FLUJOS DE INVERSIÓN

(En millones de euros)

\begin{tabular}{|l|c|c|c|c|}
\hline \multirow{2}{*}{ Año } & \multicolumn{2}{|c|}{ Japón en España } & \multicolumn{2}{c|}{ España en Japón } \\
\cline { 2 - 5 } & Inversión bruta & Inversión neta & Inversión bruta & Inversión neta \\
\hline 2000 & 88,45 & - & 11,25 & $-18,07$ \\
2005 & 187,30 & - & 50,22 & 36,20 \\
2010 & 108,95 & - & 14,40 & 11,16 \\
2012 & 55,31 & 18,09 & 1,86 & 1,86 \\
2013 & 176,02 & 141,82 & 4,28 & 6,28 \\
2014 & 459,76 & 428,88 & 6,37 & 3,20 \\
2015 & 555,18 & 552,43 & 6,89 & 0,37 \\
2016 & 509,11 & 463,18 & 0,37 & 2,73 \\
2017 & 161,65 & 137,54 & 3,00 & 0,31 \\
2018 & 898,84 & 810,24 & 0,31 & 0,00 \\
2019 (ene-mar) & 72,81 & 72,81 & 0,00 & \\
\hline Fuente: Subdirección General de Comercio Internacional de Inversiones. &
\end{tabular}


LAS RELACIONES COMERCIALES Y DE INVERSIÓN ENTRE ESPAÑA Y JAPÓN...

CUADRO 7

POSICIÓN DE INVERSIÓN

(En millones de euros)

\begin{tabular}{|l|c|c|c|c|c|c|}
\hline \multicolumn{2}{|c|}{ Año } & \multicolumn{3}{|c|}{ Japón en España } & \multicolumn{3}{c|}{ España en Japón } \\
\cline { 2 - 7 } & Posición global & $\mathbf{N}^{\circ}$ empresas & Empleo & Posición global & N. $^{\circ}$ empresas & Empleo \\
\hline 2010 & $3.708,84$ & 148 & 29.130 & 81,30 & 16 & 11.268 \\
2011 & $2.987,66$ & 145 & 26.161 & 251,21 & 17 & 3.534 \\
2012 & $3.634,50$ & 149 & 25.768 & $-98,54$ & 16 & 1.377 \\
2013 & $3.562,06$ & 149 & 26.169 & 189,99 & 17 & 4.679 \\
2014 & $3.913,57$ & 158 & 24.457 & 204,42 & 19 & 4.584 \\
2015 & $4.230,13$ & 169 & 28.738 & 252,68 & 24 & 5.541 \\
2016 & $6.602,11$ & 184 & 39.149 & 194,91 & 26 & 5.464 \\
2017 & $6.712,45$ & 184 & 40.718 & 272,83 & 26 & 5.201 \\
\hline Fuente: Subdirección General de Comercio Internacional de Inversiones.
\end{tabular}

comerciales y la inversión, sobre todo, a raíz de la entrada en vigor del Acuerdo de Asociación Económica (Economic Partnership Agreement, EPA) entre la Unión Europea (UE) y Japón, el 1 de febrero de 2019, que abre nuevas oportunidades de mercado para las empresas españolas.

Con esa idea, en el marco del Plan de Acción para la Internacionalización de la Economía Española 2019-2020, aprobado por el Consejo de Ministros el 29 de marzo de 2019, se contempla una serie de medidas, entre las que destaca la de continuar favoreciendo la diversificación de los mercados y sectores de destino de las exportaciones españolas de bienes y servicios. Con ese objetivo, mediante un análisis cuantitativo y cualitativo de áreas geográficas y de sectores de oportunidad, se ha puesto en marcha la Estrategia PASE (Países con Actuación Sectorial Estratégica), y Japón ha sido uno de los primeros países seleccionados.

Los motivos que han llevado a elegir a Japón como país PASE tienen que ver con su importancia económica (es la 3..$^{\text {a }}$ potencia económica, detrás de Estados Unidos y China, con una población de 127 millones de habitantes, que goza de un elevado PIB per cápita, de
40.663 USD, según datos de 2018); comercial (4. mayor importador de mercancías y $8 . \circ$ importador de servicios a nivel mundial); y de inversión (2.. mayor emisor mundial de flujos de inversión directa extranjera, IDE, en 2017 y 6. en stock IDE en el exterior).

También se han tenido en cuenta otros factores, como el éxito de la estrategia Abenomics (que ha logrado revertir dos décadas de estancamiento y deflación), adoptada por el primer ministro Abe en $2012^{12}$; la visibilidad internacional que va a tener Japón con motivo de los muchos eventos que se han desarrollado o se van a desarrollar en su territorio (sede del G20, Juegos Olímpicos y Paralímpicos en 2020, Expo de Osaka en 2025), lo que lo convierte en escaparate de entrada para otros mercados asiáticos; la entrada en vigor del mencionado EPA UE-Japón; y los retos derivados de la disminución y el envejecimiento de la población ${ }^{13}$.

12 Abenomics tenía como objetivo convertir a Japón «en el mejor país mundial para los negocios». Se identificaron tres «flechas» con el objetivo de alcanzar un crecimiento real del $2 \%$ : 1) política monetaria fuertemente expansiva con un objetivo de inflación del $2 \%$; 2) política fiscal flexible para alcanzar el equilibrio presupuestario en 2020, simultaneando estímulos fiscales en caso necesario; y 3) paquete de reformas estructurales destinadas a mejorar la tasa de crecimiento potencial.

13 Japón ha puesto en marcha la Estrategia Sociedad 5.0 tendente a integrar el ciberespacio y el espacio físico. 
Las actuaciones recogidas en el PASE de Japón se centran en aquellos sectores en los que la oferta exportable española se ajusta a las necesidades del mercado japonés y donde las empresas españolas cuentan con un amplio margen de mejora para consolidar su presencia en ese país. EI PASE prioriza también el posicionamiento de España como destino de la inversión japonesa y el desarrollo de proyectos conjuntos de empresas de ambos países en terceros mercados.

La Secretaría de Estado de Comercio (SEC), a través de ICEX, está fomentando la diversificación de la oferta exportable en este mercado, llevando a cabo actividades de promoción de productos farmacéuticos, biotecnológicos, químicos, nanotecnológicos, en tratamiento de aguas, ciudades inteligentes, energía, aeronáutica y en otros sectores industriales y de servicios.

Hasta la fecha, las empresas españolas han sabido aprovechar las oportunidades de negocio en los sectores de bienes de consumo, hábitat, calzado y moda textil, así como en los productos agroalimentarios (cárnicos —sobre todo porcino-, vino, aceite de oliva, pescado), pero la calidad de los productos españoles hace que todavía exista un amplio margen de mejora en dichos sectores, a pesar de algunas limitaciones en el acceso al mercado.

Por tales motivos, en el PASE de Japón se fijan una serie de sectores estratégicos que se verán favorecidos por la reciente entrada en vigor del EPA UE-Japón:

- Sector agroalimentario: carne de porcino, vinos y bebidas alcohólicas, productos de la pesca, productos lácteos, carne de bovino, frutas y hortalizas y productos agrícolas transformados (PATS). Además, 42 indicaciones protegidas españolas se verán amparadas igualmente por el Acuerdo de Asociación Económica.

- Automoción.

- Productos industriales.

- Farmacéuticos.

- Textiles.

Las energías limpias, eólica (onshore y offshore) y fusión nuclear (aceleradores) y los proyectos y alianzas conjuntas en terceros mercados son otros sectores estratégicos recogidos en el PASE que pueden suponer oportunidades de mercado para las empresas españolas.

Además, el desmantelamiento de centrales nucleares y la gestión de residuos radiactivos, ámbitos en los que España cuenta con una amplia experiencia, también presentan oportunidades para las empresas de nuestro país.

Por otra parte, el METI ha definido como sectores prioritarios en los próximos años, entre otros, las tecnologías de la información y la comunicación (TIC), la robótica y la inteligencia artificial, la biotecnología y el sector de las energías renovables.

\section{Cooperación empresarial}

La relación entre España y Japón en el ámbito económico va más allá de los datos bilaterales de comercio e inversión, puesto que ahora mismo la colaboración y las alianzas entre las empresas de ambos países en los terceros mercados ofrecen un gran abanico de posibilidades. Los sectores que se consideran estratégicos en el PASE para esta cooperación son sobre todo las infraestructuras (agua, energía, transporte) y el industrial (automoción).

La experiencia y el potencial de las empresas españolas en el sector de las energías renovables están haciendo que se $\triangleright$ 
intensifiquen las relaciones con las instituciones japonesas en materia de energía fotovoltaica, eólica y marina.

El interés estratégico de esta colaboración económica y comercial gira en gran medida en torno a las operaciones conjuntas de empresas de ambos países en terceros mercados. La mayor implantación de las compañías españolas en Latinoamérica, Europa y África, y la experiencia de sus homólogas japonesas en Asia pueden ser elementos complementarios ventajosos para ambas partes. De hecho, las grandes corporaciones japonesas desarrollan grandes proyectos con empresas españolas en estas y otras zonas.

El interés que despiertan las operaciones conjuntas en terceros mercados ha dado lugar a que un buen número de grandes empresas españolas disponga ya de oficinas de representación en Japón, cuya función principal es estrechar relaciones con las centrales de las grandes multinacionales de ese país con objeto de explorar oportunidades de negocio en terceros mercados.

En la actualidad hay aproximadamente unas ochenta empresas españolas establecidas en el mercado japonés y la mayoría de ellas son de los sectores de alimentación y bebidas, moda, energías renovables, servicios, automoción e industrias culturales.

La Secretaría de Estado de Comercio (SEC) ha venido impulsando las reuniones institucionales y los contactos con las autoridades japonesas competentes $\left(\mathrm{JICA}^{14}, \mathrm{JBIC}^{15}\right.$ ) con el fin de estudiar fórmulas que permitan, si fuera posible, la cofinanciación de proyectos en paralelo u otras formas de cooperación, especialmente en la región asiática. Por el momento, se

4 Japan International Cooperation Agency.

15 Japan Bank for International Cooperation. han mantenido varias reuniones con ambas instituciones explicando las particularidades del FIEM ${ }^{16}$ comercial y del FIEM concesional. La SEC mantiene también estrechos contactos con JETRO, que está cooperando en el establecimiento de empresas españolas en Japón.

Dentro de esta estrategia de cooperación, la agenda institucional juega un papel importante gracias al Diálogo Económico y Comercial contemplado en el MOU firmado con el METI durante la visita de SS MM los Reyes de España a Japón en 2017 y a las reuniones anuales del Comité Bilateral Hispano-Japonés de cooperación empresarial, cuya organización corre a cargo de la Cámara de Comercio de España y de la Cámara de Comercio e Industria de Japón.

En ambos casos, las empresas tienen la oportunidad de reforzar sus contactos y posibles estrategias conjuntas con el apoyo del marco institucional. En paralelo, la organización de eventos empresariales y seminarios sectoriales contribuye igualmente a esta estrategia de cooperación empresarial.

\section{Conclusión}

Las relaciones económicas entre España y Japón se han incrementado notablemente desde los años ochenta del siglo pasado hasta alcanzar un nivel importante en la actualidad. Los intercambios comerciales de bienes muestran, en general, un saldo favorable a Japón, aunque la tasa de cobertura haya ido aumentando paulatinamente, si bien con algunos altibajos. Las relaciones de inversión ofrecen también una situación favorable a Japón, pues sus flujos y su stock son mucho más elevados $\triangleright$

16 Fondo para la Internacionalización de la Empresa. 
que los de España en ese país. Sin embargo, en el comercio de servicios el saldo es favorable a España.

A pesar de la evolución positiva de las relaciones económicas bilaterales y de que Japón sea ya el segundo socio comercial de España en Asia (solo superado por China), existe todavía un amplio margen de mejora. Se espera que la entrada en vigor del EPA UE-Japón y el plan PASE sirvan de impulso para las relaciones comerciales a la vista de las nuevas oportunidades de mercado que se abren como consecuencia de la remoción de barreras técnicas al comercio.

Pero el interés estratégico de la relación económica y comercial va a girar también en torno a las operaciones conjuntas de empresas de ambos países en terceros mercados. La mayor implantación y conocimiento de las empresas españolas en América Latina y África, y la tradición y experiencia de las japonesas en Asia pueden traducirse en beneficios mutuos. 